\title{
Epidemiological burden of heart failure
}

\author{
L Tavazzi
}

Despite the considerable burden in terms of suffering and loss of life, and despite its economic impact on health services in terms of frequent hospitalisation and long term drug treatment, relatively little is known about the epidemiology of heart failure. ${ }^{1-23}$ The impact of heart failure on society is expected to increase as the survival benefit associated with medical and surgical interventions improves, and as the proportion of the elderly within the community increases.

The fact that the reported incidence and prevalence of heart failure varies reflects differences in methodology rather than differences between populations. The principal shortcomings in estimating incidence and prevalence are related to the absence of a universally agreed definition of heart failure, the difficulty in recognising the syndrome clinically, and the lack of investigations that can confirm the diagnosis.

The overall prevalence of heart failure lies between 3 and 20 per 1000 population, but exceeds 100 per 1000 among those older than 65. The annual incidence lies between 1 and 5 per 1000, and approximately doubles each decade after the age of $45 .{ }^{1-23}$ Despite the variability of these estimates there is little doubt that heart failure is a considerable public health problem.

This article reviews the causes and risk factors associated with the development and evolution of the syndrome as a rationale for evaluating preventive measures. It also discusses the organisational and economic implications of the disease in terms of public health resource allocation.

\section{Causes of heart failure}

The fact that heart failure is a common end point of various cardiac diseases means that its aetiology is of obvious importance in planning effective preventive strategies. However, the criteria that have been used to determine the cause of heart failure have varied between different studies.

The recent Framingham report confirmed the high prevalence of arterial hypertension as a major cause of heart failure: $91 \%$ of patients with heart failure in that study had a history of hypertension. ${ }^{24}$ Hypertensive heart failure was also shown to have a poor outcome. However, other community based studies indicate that hypertension is a less common cause of heart failure. An overview of 31 studies indicated that myocardial ischaemia was responsible for heart failure in approximately $50 \%$ of cases, and hypertension was identified as an aetiological factor in only $4 \%$ of cases. The true estimate for the population as a whole probably lies between these two extremes. In a survey performed in Italian hospital cardiological units, heart failure was considered to be primarily of hypertensive origin in about $15 \%$ of cases. ${ }^{25}$

These data show that coronary heart disease and hypertension (either singly or together) account for the great majority of cases of heart failure within the developed world, whereas rheumatic heart disease and nutritional cardiac disease are more common causes in the developing world. Thus, heart failure is more frequent in elderly populations in developed countries and in younger age groups in underdeveloped countries.

\section{Risk factors for heart failure}

The identification of risk factors for heart failure is important in terms of pinpointing individuals at risk and adopting appropriate preventive strategies. The community based risk profile in the general population differs from that in patients with specific disease related heart failure and from that in the group of patients who participate in clinical trials. Both the indicators and their relevance change depending on the population being studied.

The most significant risk factors in the community based Framingham study were signs of left ventricular hypertrophy and diabetes. ${ }^{26}$ Data from various sources indicate that reduced glucose tolerance is also an important determinant of progressive impairment of heart function.

Racial differences in incidence and mortality from heart failure have been noted in several studies. A study in the United States reported that African-American men have a $33 \%$ greater risk of being hospitalised for the treatment of heart failure than white men. In the same study the risk among AfricanAmerican women was $50 \%$ greater than among white women. ${ }^{27} \mathrm{~A}$ recent retrospective cohort study in 64877 patients enrolled in a large health maintenance organisation programme in the United States confirmed these findings, showing that mortality from heart failure was approximately 2.5 times higher among African-Americans than among whites younger than $65 . .^{28}$ In the latter study the mortality rates converged among older patients. The racial differences observed in both studies are likely to be related to the higher prevalence of hypertension and diabetes in African-
Cardiology Division, 27100 Pavia, Italy

L Tavazzi

Correspondence to: Professor Tavazzi. 
Americans than in white patients. These findings support the hypothesis that coronary heart disease, hypertension, and diabetes are the leading causes of heart failure, and that prevention should be focused on these factors.

\section{Impact on health resources}

A number of studies highlight the increasing demands that heart failure is placing on national health budgets. In Europe, for example, between $1 \%$ and $5 \%$ of the national health care budget is spent on heart failure. In the United States, the outpatient cost in 1991 amounted to approximately US $\$ 15$ billion and inpatient care cost US $\$ 23$ billion. The total health care cost of US $\$ 38$ billion was almost $5 \%$ of the health care expenditure in the US that year. ${ }^{29}$ It is evident that the bulk of the cost incurred in the management of heart failure is related to hospital admissions. ${ }^{892930}$ Epidemiological studies are, or will become, a major source of data with which to plan intervention strategies and budget resource distribution from the public health domain.

The number of hospital discharges with heart failure considered as the primary diagnosis increased in the past two decades. Data from various European countries (Scotland, Sweden, Holland) as well as from America indicate that hospital admissions for heart failure have almost doubled in the past 10 to 15 years. ${ }^{8929} 30$ The high readmission rate, which is characteristic of heart failure, is an important cause of increasing costs, all the more so among elderly patients for whom the readmission rates range from $29 \%$ to $47 \%$ within three to six months of the initial discharge. ${ }^{31-33}$

\section{The SEOSI study}

The Italian Association of Hospital Cardiologists (ANMCO) have undertaken a series of initiatives at a national level, the first of which was a survey: the SEOSI study (Studio sull'Epidemiologia Ospedaliera dello Scompenso in Italia). ${ }^{25}$ The objectives of the survey were fourfold: to evaluate how many patients with suspected or known heart failure are referred to a hospital cardiology unit; to assess the clinical characteristics of heart failure; to define the diagnostic and therapeutic processes adopted by cardiologists; and to evaluate the social and emotional impact of the disease on the patient.

Three hundred and fifty nine centres, uniformly distributed throughout Italy, participated in the study. The survey lasted 12 days, between 21 November and 2 December 1994, during which time all adults with proven or suspected heart failure, who were examined as outpatients or admitted as inpatients, were enrolled. As no formal diagnostic criteria were provided, a diagnosis of heart failure was made on the basis of the clinical judgment of the physician at the initial visit. This preliminary diagnosis was later confirmed at a central coordinating centre.

A definite diagnosis was made on the basis of fulfilling two major criteria or one major and two minor criteria for heart failure. Major criteria were paroxysmal nocturnal dyspnoea, orthopnoea, pulmonary congestion (estimated by physical examination and/or by chest radiography), and the presence of third heart sound. Minor criteria were signs of peripheral congestion (oedema, hepatomegaly, ascites), dyspnoea, and onset of symptoms after walking $<400 \mathrm{~m}$ in normal daily activity.

A total of 3921 patients were enrolled (table 1). A diagnosis of heart failure was confirmed by the coordinating centre in $75 \%$ of cases. The mean age of patients was 67 years (median 69 years); $25 \%$ were older than 75 . Ischaemic heart disease was the most frequent cause and $70 \%$ of patients had previously suffered a myocardial infarction. Hypertensive heart disease was considered to be the primary cause in $15 \%$ of patients. Idiopathic dilated cardiomyopathy was also diagnosed in $15 \%$ of cases Approximately half of the patients were in NYHA (New York Heart Association) class III to IV, about $50 \%$ showed physical signs of pulmonary congestion, and $33 \%$ had peripheral congestion. More than $25 \%$ of patients had previously had atrial tachyarrhythmias: atrial fibrillation was present in $27 \%$ of cases and atrial flutter in $1 \%$.

Blood chemistry, ECG, chest radiography, and echocardiography were performed on a routine basis. Ambulatory ECG was required in $35 \%$ of the cases. Exercise testing was performed in $11 \%$ of patients, in half of them with determination of oxygen consumption. Radioisotopic ventriculography was required in fewer than $3 \%$ of patients. Despite the important role of neurohormonal activation in the evolution of heart failure, procedures to assess the neuroendocrine profile of patients are poorly defined and not yet practised in hospital cardiology units.

Diuretics were given to $77 \%$ of the patients, angiotensin converting enzyme (ACE)

Table 1 Demographics and clinical characteristics of patients $(n=3921)$ enrolled in the SEOSI survey ${ }^{26}$

\begin{tabular}{lc}
\hline & $\begin{array}{c}\text { Percentage } \\
\text { of patients }\end{array}$ \\
\hline Age (years) & \\
$<65$ & 39.6 \\
65 to 75 & 35.7 \\
> 75 & 24.7 \\
Male & 60.4 \\
Aetiology & \\
Ischaemic heart disease & 33.0 \\
Idiopathic dilated cardiomyopathy & 15.3 \\
Atrial hypertension & 15.1 \\
Cardiac valve disease & 14.7 \\
Hypertrophic cardiomyopathy & 0.9 \\
Congenital heart disease & 0.4 \\
Others & 4.9 \\
Combined & 15.7 \\
Symptom duration < 2 years & 76.0 \\
NYHA functional class & \\
I & 6.9 \\
II & 43.8 \\
III & 36.0 \\
IV Unknown & 12.6 \\
Symptoms & 0.7 \\
Pulmonary congestion & \\
Peripheral congestion & 49.7 \\
Third heart sound & 33.1 \\
Able to walk < 400 m without symptoms & 32.8 \\
Tachyarrhythmias & 75.5 \\
Pacemaker & 28.2 \\
Automatic cardioverter-defibrillator & 8.7 \\
\hline
\end{tabular}

*More than one cause primarily involved. 
inhibitors to $64 \%$, digitalis to $63 \%$, and nitrates to $40 \%$. Calcium antagonists were prescribed to $32 \%$ of patients with hypertension, $24 \%$ of those with ischaemic heart disease, $12 \%$ of those with valve disease, and $6 \%$ of those with idiopathic dilated cardiomyopathy. $\beta$ Blockers were given to $6 \%$ of patients with ischaemic heart disease, to $7 \%$ with idiopathic cardiomyopathy, and to fewer than $5 \%$ of the other patients.

No significant differences were noted in drug prescriptions in relation to functional class. The median number of drugs prescribed was 3.6 in patients in functional class I, and 3.5 in patients in functional class IV. Interestingly, $32 \%$ of patients were invited to self manage the dosage of some drugs, including diuretics and anticoagulants.

The most frequent advice given by the cardiologists was salt restriction $(46 \%$ of patients). Physical activity was suggested to relatively few patients (10\%), and a formal programme of physical training was prescribed to only about $5 \%$ of the patients.

From the findings of the SEOSI study it can be estimated that in Italy about 190000 patients with suspected or known heart failure are examined in hospital cardiology units each year. Of these, approximately 65000 are likely to be admitted to hospital, and approximately $70 \%$ of all patients will have blood examinations, ECGs, and echocardiography.

Based on data generated in 1994, showing that the average length of admission for heart failure in Italy is 11 days, it follows that heart failure accounts for approximately 800000 days of hospital bed occupation each year in the cardiology unit. It is presumed that the number of patients cared for in general medical units and geriatric units is higher still. These rough data illustrate the extent of a public health problem hitherto largely unexplored.

\section{INHF database}

A second important source of epidemiological data on heart failure in Italy was accrued from the Italian Network of Heart Failure (INHF) database, managed by the ANMCO. ${ }^{34}$ The database was set up in early 1995, and in less than three years data on approximately 6000 outpatients were entered into the database by more than 130 cardiological centres uniformly distributed across Italy.

The mean age of the patients in the study was 63 years; $32 \%$ of them were older than 70 . Almost three quarters of the patients were male and $31 \%$ were in NYHA classes III-IV. Aetiology was considered to be primarily ischaemic in $50 \%$ of cases, hypertensive in $9 \%$, and idiopathic in $31 \%$ of cases. Sustained atrial tachyarrhythmias were present in $22 \%$ of patients.

ACE inhibitors were prescribed to $82 \%$ of patients, digitalis to $69 \%$, and anticoagulants to $26 \%$. $\beta$ Blockers were prescribed to $4 \%$ of the patients in 1995, and by late $1997 \beta$ blocker prescriptions had increased to $16 \%$.

The patients included in the database are a cohort of selected patients, even by virtue of the fact that they were referred for treatment to cardiological centres that were interested enough to participate in a national survey on heart failure. Although such data may not be representative of the general population of heart failure patients, it is also true that most subjects suffering from heart failure ultimately seek care at a cardiological centre when symptom control becomes difficult.

The data analysed in the INHF database is, therefore, likely to represent a large sample of patients with relatively advanced disease or with a clinical syndrome of difficult aetiological diagnosis. This may account for the high prevalence of idiopathic aetiology.

It is expected that epidemiological information and prognostic features emerging over the next few years will provide a dynamic picture of the clinical evolution of heart failure and its medical management. This process of prognostic stratification will assist in the preparation of national guidelines for implementation within the Italian cardiological community.

1 Epstein FH, Ostrander LD, Johnson BC, et al. Epidemiological studies of cardiovascular disease in a total community-Tecumseh, Michigan. Ann Intern Med 1965;62:1170-187.

2 Garrison GE, McDonough JR, Hames CG, et al. Prevalence of chronic congestive heart failure in the population of Evans County, Georgia. Am $\mathcal{F}$ Epidemiol 1966; 83:338-44.

3 Gibson TC, White KL, Klainer LM. The prevalence of congestive heart failure in two rural communities. $\mathcal{f}$ Chromic Dis 1966:19:141-52.

4 Landhal S, Svanborg A, Astrand K. Heart volume and the prevalence of certain common cardiovascular disorders a 70 and 75 years of age. Eur Heart $\mathcal{F} 1984 ; 5: 326-31$

5 Gillum RF. Heart failure in the United States 1970-1985. Am Heart f 1987;113:1043-45.

6 Eriksson H, Svardsudd K, Larsson B, et al. Risk factors for heart failure in the general population: the study of men born in 1913. Eur Heart $\mathcal{F} 1989 ; 10 ; 647-56$.

7 Brophy JM. Epidemiology of congestive heart failure: Canadian data from 1970 to 1989. Can $\mathcal{F}$ Cardiol 1992;8 495-8.

8 Phillips SJ, Whinant JP, O'Fallon WM, et al. Prevalence of cardiovascular disease and diabetes mellitus in residents of Rochester, Minnesota. Mayo Clin Proc 1990;65: of Roch

9 Sutton GC. Epidemiologic aspects of heart failure. $\mathrm{Am}$ Heart F 1990;120:1538-40.

10 Ghali JK, Cooper R, Ford E. Trends in hospitalization rates for heart failure in the United States, 1973-1986. Evidence for increasing population prevalence. Arch Intern Med 1990;150:796-73.

11 Shocken DD, Arriet MI, Leaverton PE. Prevalence and mortality rate of congestive heart failure in the United States. $\mathscr{f}$ Am Coll Cardiol 1992;20:301-6.

12 Remes J, Reunanen A, Aromaa A, et al. Incidence heart failure in eastern Finland: a population based surveillance study. Eur Heart f 1992;13:588-93.

13 Ambrosio CB, Riva LM, Zamboni S, et al. Lo scompemso dicuore nella popolazione: dati di prevalenza. Cardiologia 1992;37:685-91

14 Ho KKL, Pinsky JL, Kannel WB, et al. The epidemiology of heart failure: the Framingham study. $\mathcal{F}$ Am Coll Cardio 1993;22 (suppl A):6-13A

15 Rodeheffer RJ, Jacobsen SJ, Gersh BJ, et al. The incidence and prevalence of congestive heart failure in Rochester, Minnesota. Mayo Clin Proc 1993;68:1143-50.

16 McMurray J, McDonagh T, Morrison CE. Trends in hospitalization in Scotland 1980-1990. Eur Heart f 1993;14: 1158-62.

17 Garg R, Packer M, Yusuf S. Heart failure in 1990s: evaluation of a major public health problem in cardiovascular medicine. $7 \mathrm{Am}$ Coll Cardiol 1993;22(suppl A):3-5A.

18 Andersson B, Waagstein F. Spectrum and outcome of congestive heart failure in hospitalized population. Am Heart
Am gestive heart failure

19 Ambrosio GB, Casiglia E, Spolaore P, et al. Prevalence of congestive heart failure (CHF) in the elderly. A survey from a population in the Veneto region. Acta Cardio 1994;49:324-7.

20 Rengo F, Acanfora D. Lo scompenso cardiaco nell'anziano. G Ital Cardiol 1994;24:1423-34.

21 Sinagra GF, Perkan A, Zecchin M, et al. L'epidemiologia dello scompenso cardiaco: un problema crescente d sanita' pubblica. G Ital Cardiol 1995;25:1043-53.

22 Schocken DD, Arrieta MI, Leaverton PE, et al. Prevalence 
and mortality rate of congestive heart failure in the United States. F Am Coll Cardiol 1992;20:301-6.

23 Cowie MR, Mosterd A, Wood DA, et al. The epidemiology of heart failure. Eur Heart $\mathcal{f}$ 1997;18:208-25.

24 Levy D, Larson MG, Vasan RS, et al. The progression from congestive heart failure. $\mathcal{F} A M A-1996$; 275:1557-62.

25 The SEOSI Investigators. Survey on heart failure in Italian hospital cardiology units. Results of the SEOSI study. Eur Heart $\mathcal{F} 1997 ; \mathbf{1 8}: 1457-64$.

26 Kannel WB, Ho K, Thom T. Changing epidemiological features of cardiac failure. Br Heart $\mathcal{F}$ 1994;72(suppl):53-9.

27 Gordon HS, Harper DL, Rosenthal GE. Racial variation in predicted and observed in-hospital death. $\mathscr{f} A M A$ 1996;276:1639-44.

28 Alexander M, Grumbach K, Selby J, et al. Hospitalization for congestive heart failure. $\mathcal{F A M A}$ 1995;274:1037-42.
29 O'Connell JB, Bristow MR. Economic impact of heart fail ure in the United States: time for a different approach. $f$ Heart Lung Transp 1993;13(suppl):S107-12.

30 Eriksson $\mathrm{H}$. Heart failure: a growing public health problem F Intern Med 1995;237:135-41.

31 Gooding J, Jette AM. Hospital readmission among the elderly. F Am Geriatr Soc 1985;33:395-401.

32 Rich MW, Freedland KE. Effect of DRGs on the threemonth readmission rate of geriatric patients with congesmonth readmission rate of geriatric patients with con

33 Vinson JM, Rich MW, Sperry JC, et al. Early readmission of elderly patients with congestive heart failure. $\mathcal{J} \mathrm{Am}$ Geriatr Soc 1990;38:1290-5.

34 Maggioni AP, Lucci D, Gorini $\mathrm{M}$, et al, for the IN-CHF investigators: ACE-inhibitor utilization in congestive heart failure: a survey on 2343 Italian outpatients. $\mathcal{f} \mathrm{Am}$ Coll Cardiol 1997;29:324-5A. 